\title{
Umbrella occlusion of persistent arterial duct in children under two years
}

\author{
M A Gatzoulis, M L Rigby, A N Redington
}

\begin{abstract}
Objective-To assess the use of transcatheter occlusion of a persistent arterial duct in symptomatic children $<2$ years of age.

Design-Descriptive study of selected, non-randomised infants with persistent arterial duct who underwent attempted umbrella occlusion.

Setting-Tertiary referral centre.

Patients-Between June 1990 and April 1993, 29 young children with a symptomatic persistent arterial duct underwent attempted transcatheter occlusion. Their age ranged from 1.5 to 23 months, with the youngest infant weighing $2.9 \mathrm{~kg}$. The diagnosis was established before operation in all patients by cross sectional echocardiography.
\end{abstract}

Interventions-Transcatheter occlusion of a haemodynamically important persistent arterial duct was performed with the Rashkind ductal umbrella. In the past year the front loading technique has been used to place the $12 \mathrm{~mm}$ umbrella through a $6 \mathrm{~F}$ (French) sheath and the $17 \mathrm{~mm}$ device through a $8 \mathrm{~F}$ sheath so extending the indications for their use. Results-Umbrellas were successfully placed in $25(86 \cdot 2 \%)$ infants and there was symptomatic improvement in all. There were no deaths or severe complications. The four failures occurred early in the series. They were caused by kinking of the $11 \mathrm{~F}$ sheath in two cases and embolisation into the left pulmonary artery in one case. The procedure was abandoned in the fourth case because of a large duct. Only three of the 25 patients had small residual shunts at one year follow up (all with $17 \mathrm{~mm}$ devices) but no stenosis or turbulence was noted in any of the patients.

Conclusion-The transcatheter occlusion of persistent arterial duct in young chil-

Department of Paediatric Cardiology, Royal Brompton Hospital, London M A Gatzoulis M L Rigby

A N Redington

Correspondence to Dr AN Redington, Department of Paediatric Cardiology, Royal Brompton Hospital, Sydney Street, London SW3 6NP.

Accepted for publication 2 March 1994
Transcatheter closure of the persistent arterial duct with the Rashkind umbrella is an estab- lished alternative to surgery, and in many units has become the treatment of choice for children and adults. Most paediatric patients in reported series were beyond infancy, ${ }^{1-3}$ the main indication for elective ductal closure was to eliminate the risk of infective endarteritis. The purpose of this study is to assess the effectiveness of catheter occlusion on symptomatic infants with a haemodynamically important persistent arterial duct, with special reference to the new delivery technique of front loading the Rashkind umbrella, ${ }^{4}$ which enables its use even in small infants.

\section{Patients and methods}

PATIENTS

Between June 1990 and April 1993, 29 infants with a persistent arterial duct underwent elective transcatheter occlusion with a Rashkind umbrella. Their median (range) age was $13(1,5-23)$ months and weight $7 \cdot 5$ $(2 \cdot 9-12 \cdot 3) \mathrm{kg}$. The diagnosis was suspected clinically and confirmed by cross sectional echocardiography in all. Additional diagnoses were of Down's syndrome in three infants, small restrictive ventricular septal defect in one, and generalised arteriopathy with severe dilatation of the aorta in another. Prematurity, bronchopulmonary dysplasia, and hypospadias in combination with failure to thrive due to increased pulmonary blood flow through a persistent arterial duct was the complete diagnosis in the smallest infant who weighed $2.9 \mathrm{~kg}$. This infant was referred to us after he had had surgery elsewhere. A ductal clip had been placed through a left thoracotomy, but he was left with a considerable residual shunt $(\mathrm{Qp} / \mathrm{Qs}=3 \cdot 2 / 1)$. The residual arterial duct was occluded four weeks later (fig 1) with a front loaded $12 \mathrm{~mm}$ umbrella through a $6 \mathrm{~F}$ Mullins sheath. The ductal shunt was completely abolished with immediate symptomatic improvement.

All of the other patients were symptomatic with breathlessness at rest, failure to thrive, or recurrent chest infections. Four infants were receiving diuretic treatment. Patients were selected on the basis of a clinical and echocardiographic diagnosis of persistent arterial duct and their suitability for transcatheter closure. We excluded patients with very large tubular ducts with no obvious stenosis at the pulmonary artery end. Early in the series, before the front loading technique was used, infants weighing $<5 \mathrm{~kg}$ were included only under 
Figure 1 Infant $(2.9 \mathrm{~kg})$ with bronchopulmonary dysplasia and failed surgical closure of a persistent arterial duct: (A) residual ductal shunt of about $2.5 \mathrm{~mm}$; (B) shows $12 \mathrm{~mm}$ umbrella positioned next to surgical clip. $P A$, pulmonary artery; $P D A$, persistent ductus arteriousus; $A O$, aorta.
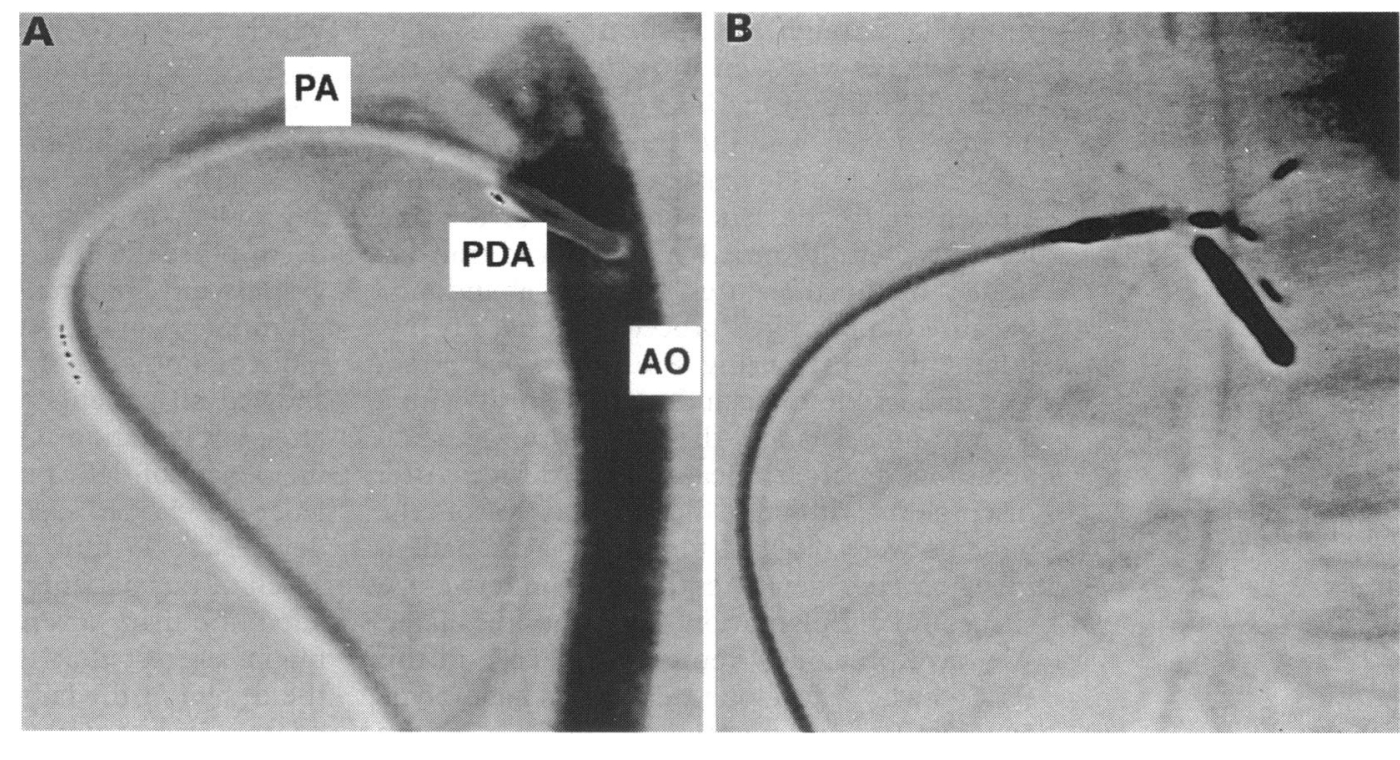

exceptional circumstances. The parents were offered either the umbrella closure or surgery after full discussion, and transcatheter occlusion was attempted only with their written consent.

\section{PROCEDURE}

All procedures were performed under general anaesthesia. A $6 \mathrm{~F}$ multipurpose catheter was placed transvenously and a $4 \mathrm{~F}$ pigtail catheter was inserted transarterialy through valved introducers in the groin. The size of

Front loading umbrella technique for ductal closure

\begin{tabular}{llllll}
\hline $\begin{array}{l}\text { Age } \\
\text { (months) }\end{array}$ & $\begin{array}{l}\text { Weight } \\
(\mathrm{kg})\end{array}$ & $\begin{array}{l}\text { Umbrella } \\
(\mathrm{mm})\end{array}$ & $\begin{array}{l}\text { Sheath } \\
(\mathrm{F})\end{array}$ & Complications & Follow up \\
\hline 1.5 & 2.9 & 12 & 6 & $\begin{array}{l}\text { Stenosis of } \\
\text { left pulmonary artery }\end{array}$ & $\begin{array}{l}\text { Resolved, } \\
\text { no shunt }\end{array}$ \\
12 & 7.6 & 17 & 8 & None & Shunt + \\
19 & 8.5 & 17 & 8 & None & Shunt + \\
\hline
\end{tabular}

Shunt + , small leak on colour Doppler.

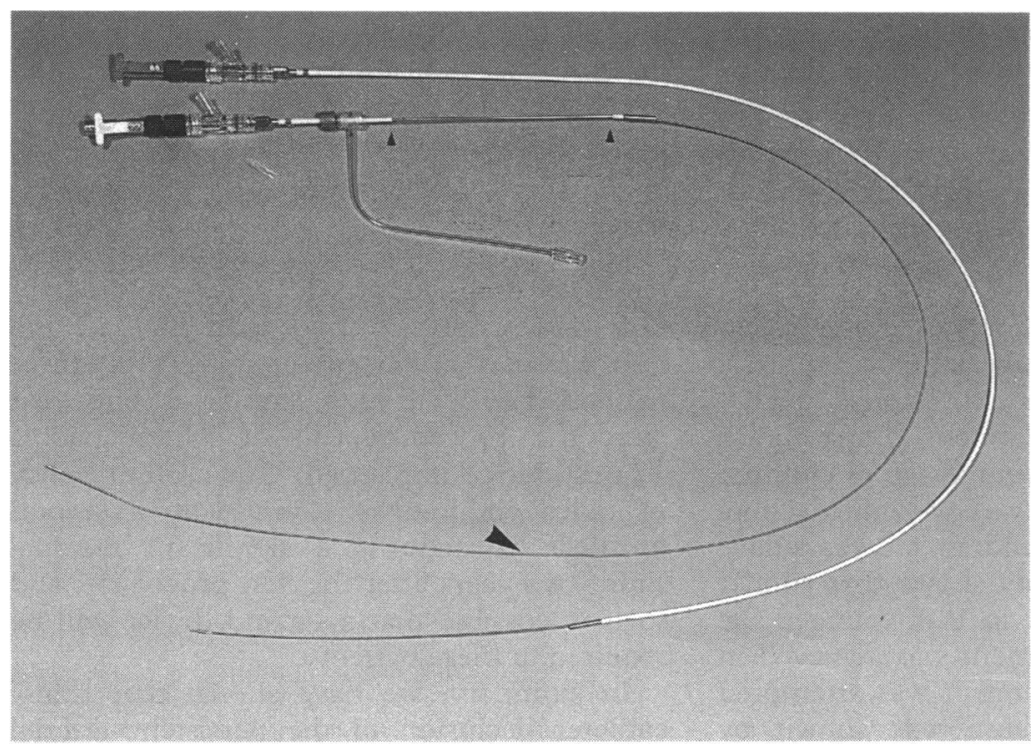

Figure 2 Standard delivery system (outside), with stripped system (inside); note much longer double wire exposed (large arrow), after removing most of the catheter (small arrows). the duct at its narrowest point was measured by aortography in the lateral projection, with the venous catheter in the main pulmonary artery for reference. For ducts measuring $<4 \mathrm{~mm}$ in internal diameter the $12 \mathrm{~mm}$ device was used, for larger ducts $(4-7 \mathrm{~mm})$ the $17 \mathrm{~mm}$ umbrella was implanted. The venous approach was adopted in all but one patient. In 26 patients the $8 \mathrm{~F}$ and $11 \mathrm{~F}$ Mullins trans-septal sheaths were used to position the $12 \mathrm{~mm}$ and $17 \mathrm{~mm}$ umbrellas. ${ }^{5}$

The front loading umbrella technique 4 enabled successful transcatheter closure of a persistent arterial duct in three patients (table). The main advantage of this technique is that it allows an umbrella to be implanted through a smaller trans-septal sheath by reducing the external diameter of the delivery system. This reduction is achieved by removing the outer catheter of the current delivery system (fig 2). The umbrella is either folded in the metal pod in the usual way and advanced into the sheath from the pod, or advanced from the Perspex folding device directly into the long sheath after opposing it to the mouth of the sheath. The rest of the technique differs from the conventional one, only in the care required to avoid bending the delivery system as it is advanced along the sheath.

All patients had imaging by colour flow Doppler examination within 24 hours of occlusion and serially during follow up at six monthly intervals. Particular attention was paid to the detection of any pulmonary artery or aortic stenosis or distortion, or turbulent flow on detailed colour flow mapping.

\section{Results}

Successful place of the umbrella was achieved in $25(86.2 \%)$ infants. There were no deaths or serious procedural complications. Eighteen $12 \mathrm{~mm}$ and seven $17 \mathrm{~mm}$ devices were used. The front loading umbrella technique was used successfully in three infants $(12 \mathrm{~mm}$ umbrella through a $6 \mathrm{~F}$ sheath in one, $17 \mathrm{~mm}$ 
umbrella through a $8 \mathrm{~F}$ sheath in two). The four failures were encountered early in the series. Kinking of the long $11 \mathrm{~F}$ sheath with a $17 \mathrm{~mm}$ device was the reason for failure in two cases. In one case a $12 \mathrm{~mm}$ umbrella embolised to the left pulmonary artery and was successfully snared and retrieved transvenously but further attempts were abandoned because of prolonged procedure time. Finally, a large duct measuring $>9 \mathrm{~mm}$ in one infant was impossible to occlude satisfactorily with a $17 \mathrm{~mm}$ umbrella and the procedure was again abandoned before release of the device. After discussion with the parents three of the patients were referred for surgery, the patient in whom the device embolised underwent a successful implantation two months later. We have previously reported one case in this series who developed severe haemolytic anaemia after placement of a $17 \mathrm{~mm}$ umbrella. $^{6}$ A second $17 \mathrm{~mm}$ device was implanted four weeks later to completely stop the shunt and resolve the haemolysis.

Follow up ranged from three to 29 months with a mean of 13 months. There was resolution of symptoms in all patients. Only two infants had clinically evident residual shunts at last follow up (both had a $17 \mathrm{~mm}$ umbrella), the rest were detected only on echocardiography. Colour flow Doppler showed ductal shunts in 13 children $(55.4 \%)$ on the first day and seven $(26.3 \%$ ) after six months. At most recent follow up, only three patients had residual shunts, all had been followed up for $>1$ year. Residual shunts on colour flow mapping were found at six months after implantation in all seven infants who had the $17 \mathrm{~mm}$ umbrella and these persisted in three at one year. Conversely all 18 children who had the $12 \mathrm{~mm}$ umbrella had no clinical or colour Doppler evidence of residual shunting at six months. There were two cases with turbulent colour flow in the left pulmonary artery (one with a $17 \mathrm{~mm}$, one with a $12 \mathrm{~mm}$ device) without obvious pressure gradient at the time of the study. This has resolved by one year in both. In the smallest child there was turbulence in the descending aorta due to protrusion of the distal arms. There was no pressure gradient but turbulence has persisted at the most recent follow up six months after the procedure.

\section{Discussion}

Previous studies have confirmed the safety and effectiveness of transcatheter umbrella occlusion of the persistent arterial duct. ${ }^{78}$ Indeed, it is now the treatment of first choice in many centres. The average age of children in these earlier reports was well into school age and relatively few children $<2$ years have been reported. Our study shows that similar results can be achieved in this younger age group. Successful placement was achieved in 26 of 29 children in whom it was attempted $(89.6 \%)$, complete closure was shown by colour flow mapping in 23 of them (88.4\%). There was only one patient with an important complication, that of severe haemolysis, which resolved with placement of a second device. ${ }^{6}$ A previous study by Musewe and coworkers has highlighted the potential problem of left pulmonary arterial stenosis. ${ }^{7} \mathrm{We}$ were particularly concerned that this might be a problem in our younger and smaller children, but detailed cross sectional echocardiography and colour flow mapping showed left pulmonary artery turbulence in only two patients immediately after the procedure and showed all patients to be normal six months after implantation. Ottenkamp et al found an incidence of left pulmonary arterial turbulence of $5.5 \%$, seen only with the $17 \mathrm{~mm}$ device. ${ }^{8}$ A $17 \mathrm{~mm}$ device was used in only seven of our patients and the low incidence of left pulmonary artery problems in our series might suggest that the problem is related to the design of the larger device rather than the relative size of umbrella and artery. If this is the case, then earlier closure in smaller children with more frequent use of the $12 \mathrm{~mm}$ device may ultimately prove to be less complicated. We did not see any tricuspid valve damage or regurgitation on echocardiographic screening at the end of the procedure or during follow up. Although one paper reports transoesophageal echocardiographic monitoring of interventional cardiac catherisation, ${ }^{9}$ and a more recent paper has reported damage to the tricuspid valve during balloon dilatation of the pulmonary valve in children $>6$ months of age, ${ }^{10}$ this does not seem to be a problem even with the use of relatively large delivery catheters. Therefore monitoring by means of transesophageal echocardiography during umbrella occlusion of a persistent arterial duct in children $<2$ years, although advocated by some, is not essential.

The front loading technique, described by Perry and Lock enables the umbrella to be delivered through a smaller trans-septal sheath and therefore to smaller infants. ${ }^{4}$ They positioned the $12 \mathrm{~mm}$ umbrella through a $7 \mathrm{~F}$ and the $17 \mathrm{~mm}$ through a $9 \mathrm{~F}$ sheath. We have gone down still further in size, positioning the $12 \mathrm{~mm}$ umbrella through a $6 \mathrm{~F}$ and the $17 \mathrm{~mm}$ through a $8 \mathrm{~F}$ sheath. This extends the indications of the device and overcomes the problem of kinking of larger long sheaths in small children, which led to failure in two of the patients in the early part of the series.

Our incidence of residual shunts is no different to other reports in older children. ${ }^{112}$ Our $100 \%$ closure rate with the $12 \mathrm{~mm}$ device is particularly encouraging. Only three patients had persisting shunts at one year after the procedure, all of whom had a $17 \mathrm{~mm}$ device implanted. Our current policy in older children is to implant a second umbrella if there is a significant residual shunt two years after the first procedure, and so it is possible that a second device will be required in these patients.

In summary, we have shown that transcatheter occlusion of the persistent arterial duct is effective and safe in small children. Front loading the device into a smaller sheath extends the age and size limits of the proce- 
dure and does not seem to increase the risk of complications. As a consequence, catheter closure has become the treatment of choice for the persistent arterial duct even in small infants in our hospital.

1 Dyck J, Benson L, Smallhorn J, McLaughlin P, Freedom $R$, Rowe $R$. Catheter occlusion of the persistently patent ductus arteriosus. $A m \neq$ Cardiol 1988;62: 1089-92.

2 Hosking M, Benson L, Musewe N, Dyck J, Freedom R. Transcatheter occlusion of the persistently patent ductus arteriosus. Circulation 1991;84:2313-17.

3 Latson L, Hofschire P, Kugler J, Cheatham J, Gumbiner C, Danford D. Transcatheter closure of patent ductus arteriosus in pediatric patients. $\mathcal{F}$ Pediatr 1989;115: 549-53.

4 Perry S, Lock J. Front-loading of double-umbrella devices, a new technique for umbrella delivery for closing cardiovascular defects. Am $\mathcal{f}$ Cardiol 1992;70:

5 Rashkind W, Mullins C, Hellenbrand W, Tait $M$.
Nonsurgical closure of patent ductus arteriosus: clinical application of the Rashkind PDA occluder system. Circulation 1987;75:583-92.

6 Hayes AM, Redington AN, Rigby ML. Severe haemolysis after transcatheter duct occlusion: a non-surgical remedy. Br Heart f 1992;67:321-2.

7 Musewe N, Benson L, Smallhorn J, Freedom R. Twodimensional echocardiographic and color flow Doppler evaluation of ductal occlusion with the Rashkind prosthesis. Circulation 1989;80:1706-10.

8 Ottenkamp J, Hess J, Talsma M, Buis-Liem T. Protrusion of the device: a complication of catheter closure of patent ductus arteriosus. Br Heart $\mathcal{f}$ 1992;68:301-3.

9 Stumper $O$, Witsenburg $M$, Sutherland GR, CrommeDijkhuis A, Godman MJ, Hess J. Transesophageal echocardiographic minitoring of interventional cardiac
catheterisation in children. $\mathcal{F}$ Am Coll Cardiol 1991; 18:1506-14.

10 Witsenburg M, Talsma M, Rohmer J, Hess J. Balloon valvuloplasty for valvular pulmonary stenosis in children over 6 months of age: initial results and long-term follow-up. Eur Heart f 1993;14:1657-60.

11 Sorenson $K$, Kristensen B, Hanson O. Frequency of occurence of residual ductal flow after surgical ligation by colour-flow mapping. Am $\mathcal{f}$ Cardiol 1991;67:653-4.

12 Latson L. Residual shunts after transcatheter closure of patent ductus arteriosus. Circulation 1991;84:2591-3. 